\title{
Novel Mullite Synthesis Based on Alumina Nanoparticles and a Preceramic Polymer
}

\author{
Enrico Bernardo ${ }^{\dagger}$ and Paolo Colombo*,‡ \\ Dipartimento di Ingegneria Meccanica-Settore Materiali, Università di Padova, via Marzolo 9, 35131 Padova, Italy \\ Eckhard Pippel and Jörg Woltersdorf \\ Max-Planck-Institut für Mikrostrukturphysik, D-06120 Halle, Germany
}

\begin{abstract}
Heating in air of a selected mixture of a silicone resin and alumina nanoparticles in the temperature range $1200^{\circ}-1500^{\circ} \mathrm{C}$ yielded dense, crack-free mullite samples. $\mathrm{Al}_{2} \mathrm{O}_{3}$, due to its nanometric size, proved to be very reactive toward silica, deriving from the ceramization of the preceramic polymer, leading to the formation of a large volume fraction of mullite crystals even at low firing temperatures $(1250 \mathrm{C})$. Because of the homogeneity of the distribution of alumina nanoparticles in the starting system, the ceramized samples exhibited a very fine microstructure consisting of crystals with an average dimension in the range of $50-300 \mathrm{~nm}$.
\end{abstract}

\section{Introduction}

$\mathrm{M}$ ULLITE ceramics are of considerable technological interest because of their combined thermal, electrical, and mechanical properties. In fact, mullite $\left(3 \mathrm{Al}_{2} \mathrm{O}_{3} \cdot 2 \mathrm{SiO}_{2}\right)$ possesses a relatively low thermal expansion coefficient $\left(\alpha_{20 / 200}=4 \times 10^{-6}\right.$ $\left.\mathrm{K}^{-1}\right)$ and consequently a high thermal shock resistance, despite a low thermal conductivity $\left(k=2.0 \mathrm{~W} \cdot(\mathrm{m} \cdot \mathrm{K})^{-1}\right)$, which makes mullite a common refractory material. ${ }^{1-3}$ Besides for thermal insulation applications, mullite has proved to be an excellent material for electrical insulation due its low electric conductivity and low dielectric constant $(\varepsilon=6.5$ at $1 \mathrm{MHz}){ }^{2}$ The combination of low dielectric constant and low thermal expansion is profitable for high-performance electronic products, especially in the field of high-density packaging: the thermal expansion, close to that of silicon, is advantageous for reducing thermal stresses arising between the chips and the ceramic substrate while the low dielectric constant allows signal processing with limited power dissipation. ${ }^{4-7}$ Finally, mullite is well known for its remarkable creep resistance, which, coupled with good mechanical strength, is useful for high-temperature structural applications. 8,9

A large variety of synthesis methods have been proposed for mullite preparation. Most of them are based on heating an alumina/silica mixture in stoichiometric proportions; the differences are related to the particular sources for the two oxides (including the use of metallic Al). Well-established procedures for mullite preparation include sol-gel processing, ${ }^{10-19}$ co-precipitation, ${ }^{20}$ hydrothermal, ${ }^{21,22}$ and chemical vapor deposition ${ }^{23}$ processes, sintering of silica-coated alumina micro- and nanopowders, ${ }^{3,24-26}$ and, above all, reaction sintering of clay and reactive alumina mixtures. ${ }^{2,4,27-29}$ The processes that do not

G. Soraru—contributing editor

\footnotetext{
Manuscript No. 21097. Received October 25, 2005; approved January 20, 2006.

${ }^{\star}$ Member, American Ceramic Society.

${ }^{\dagger}$ Author to whom correspondence should be addressed. e-mail: enrico.bernardo@ unipd.it

${ }_{\ddagger}^{\ddagger}$ Department of Materials Science and Engineering, The Pennsylvania State University, University Park, Pennsylvania.
}

include clays have the potential to yield chemically pure mullite, which is of particular interest for electronic packaging, 5,8 but because of concerns with the cost of the raw materials, some reports on the use of clay precursors for this specific application are also present in the literature. ${ }^{5}$

The various processes feature different temperatures for mullite formation. The processing of clays yields, upon heating above $980^{\circ} \mathrm{C}$, primary mullite and $\mathrm{SiO}_{2}$. This silica is capable of secondary mullite formation when clays are mixed with a suitable amount of alumina; however, the reaction is very slow at temperatures below $1587^{\circ} \mathrm{C}$ (temperature of eutectic liquid formation). ${ }^{5,27}$ Complete mullitization at lower temperatures (of the order of $1300^{\circ} \mathrm{C}$ ) is available when silica and alumina are homogeneously distributed at a nanometric scale as in the case of sol-gel processing, starting from silica gel containing alumina or boehmite $(\mathrm{AlOOH})$ nanopowders. ${ }^{18,19}$ The sol-gel processing, in addition, may allow the formation of secondary phases, giving the opportunity of producing mullite-based nanocomposites, as pointed out by Sorarù et al., ${ }^{17}$ with the formation of $\mathrm{SiC}$ within the mullite crystals. Recent work pointed out the feasibility of the production of mullite compacts from preceramic polymers, consisting of polysiloxanes, as the source for silica, filled with $\mathrm{Al}_{2} \mathrm{O}_{3}$ and $\mathrm{Al}$ particles. ${ }^{30-33}$ The general advantages of preceramic polymers are the low processing temperatures and, above all, the possibility of using polymerprocessing techniques, allowing to obtain complex shapes. Heating of preceramic polymers generally leads to the formation of cracks and pores in the ceramic products, due to the release of a great amount of gases (mainly hydrocarbons) ${ }^{34-36}$ during the polymer-to-ceramic conversion (at $T>\sim 500^{\circ} \mathrm{C}$ ), which also results in a significant volume contraction of up to $60 \%{ }^{37}$ However, the addition of secondary, filler materials (which can either react with the preceramic precursor or remain inert during firing) allows the production of ceramic monoliths with a good structural integrity upon heat treatment. ${ }^{37,38}$ The preceramic polymer-alumina (or aluminum) reaction (aided by an oxidative atmosphere that transforms the polysiloxanes into highly reactive $\mathrm{SiO}_{2}$ ) is thus a promising way to obtain mullite, as illustrated in the experiments of Suttor et al., ${ }^{30}$ Michalet et al., ${ }^{31,32}$ and Anggono et al., ${ }^{33}$ even if their experiments showed that complete mullitization was obtained only when firing in air well above $1500^{\circ} \mathrm{C}$.

The aim of the present work was to produce mullite at very low temperatures from a selected mixture of a polysiloxane preceramic polymer and alumina nanopowders, thus combining the advantages of polymer processing and the reactivity of nanoparticles.

\section{Experimental Procedure}

The preceramic polymer consisted of a polymethylsiloxane (MK, Wacker-Chemie GmbH, München, Germany) in powder 
form. It was dissolved in acetone under magnetic stirring for $15 \mathrm{~min}$, thus producing a solution with $2 \%$ solid content $(1 \mathrm{~g}$ silicone resin for $50 \mathrm{~mL}$ acetone). $\gamma-\mathrm{Al}_{2} \mathrm{O}_{3}$ nanopowders ("Aluminium oxide C," Degussa, Hanau, Germany $15 \mathrm{~nm}$ mean particle size, specific surface area of $100 \mathrm{~m}^{2} / \mathrm{g}$ ) were added to the solution, in the weight ratio silicone $/ \gamma-\mathrm{Al}_{2} \mathrm{O}_{3}=1 / 2.125$, again under magnetic stirring; this choice was suggested by considering the ceramic yield of the polymer (about $85 \mathrm{wt} \%$ ) and the stoichiometry of mullite. The mixture was ultrasonicated for $10 \mathrm{~min}$, producing a stable and homogeneous dispersion of alumina nanoparticles (according to scanning electron microscope (SEM) investigations), in which no sedimentation was observed. The dispersion was poured into a glass container and dried at $60^{\circ} \mathrm{C}$ overnight. After evaporation of the solvent, a solid silicone-alumina nanocomposite mixture was obtained, in which the nanosized filler was homogeneously distributed. The mixture was finely ground (again obtaining particles with a dimension $<10 \mu \mathrm{m}$ ) and subsequently cold pressed at $40 \mathrm{MPa}$ in a cylindrical steel die. The pressed samples (diameter $\sim 31 \mathrm{~mm}$, height $\sim 5 \mathrm{~mm}$ ) were heat treated in air at various temperatures ranging from $1150^{\circ}$ to $1550^{\circ} \mathrm{C}$, at a heating rate of $10^{\circ} \mathrm{C} / \mathrm{min}$ and a holding time of $2.5 \mathrm{~h}$. After firing, dense and crackfree ceramic samples were obtained. Samples in the preceramic form were subjected to combined differential thermal and thermogravimetric analysis (DTA/TGA, STA409, Netzsch Gerätebau $\mathrm{GmbH}$, Selb, Germany) and dilatometric analysis (402E, Netzsch Gerätebau $\mathrm{GmbH}$ ), with the same heating rate and the same atmosphere (static air) as for the heat treatments.

Structural and chemical information on the samples after thermal transformation was obtained by using SEM (Philips XL 30 ESEM, Eindhoven, the Netherlands) and transmission electron microscopy (TEM), including high-resolution or atomic plane imaging (HREM), and electron energy-loss spectroscopy (EELS), with particular emphasis on energy-loss nearedge structures (ELNES). The latter method allows to characterize the chemical bonding state in the interlayers by analyzing the fine structures of the relevant ionization edge (edge onset; shape, position, and intensity of individual peaks) that result from excitations of core-shell electrons into unoccupied states above the Fermi level. Measuring the ELNES of the relevant ionization edges is equivalent to a mapping of the partial local density of states above the Fermi level, resulting in subtle information on the respective bonding specifics and the coordination of the next neighbor atoms. The ELNES features can be interpreted by comparison with standard spectra or by quantum chemical calculations. The HREM and EELS investigations were carried out in a combined (scanning) transmission electron microscope (TEM/STEM, CM 20 FEG, Philips) having a point resolution of $0.24 \mathrm{~nm}$ and an operating voltage of $200 \mathrm{kV}$. It was equipped with a post-column electron energy filter (Gatan Imaging Filter GIF 200, model 667, Pleasanton, CA) as well as with a digital scanning module (Gatan Digiscan, Pleasanton, CA).

Samples in powder form were additionally investigated by $\mathrm{X}$-ray diffraction (XRD; Philips PW 3710), using $\mathrm{CuK} \alpha$ radiation $(0.15418 \mathrm{~nm})$. The XRD patterns were refined, according to Rietveld's method, by using the MAUD (material analysis using diffraction) program package. ${ }^{39}$

\section{Results and Discussion}

The differential thermal analysis data, coupled with the weight loss curve, are shown in Fig. 1.

The most remarkable weight loss $(\sim 7 \mathrm{wt} \%)$ occurred in the range $\sim 150^{\circ}-600^{\circ} \mathrm{C}$, and this could be attributed to different single processes, visible in both the derivative plot of TGA (Fig. 1(a)) and the DTA plot (Fig. 1(b)). The first, occurring at $270^{\circ}-290^{\circ} \mathrm{C}$ and featuring a slight exothermic peak but a relatively large weight loss, was related to the polycondensation crosslinking reaction occurring in the silicone resin, resulting in the release of water, ethanol, and methanol. ${ }^{40}$ The second one, occurring mainly at around $570^{\circ}-590^{\circ} \mathrm{C}$ and featuring a relatively strong exothermic peak, is attributable to the polymer-toceramic conversion of the preceramic polymer in an oxidative atmosphere (the large energy release being due to the combustion of the organic fraction of the polysiloxane). ${ }^{40}$ The weight loss due to the burnout of carbon is partially compensated by the intake of oxygen in the material. As observed also by Ivankovic et al., ${ }^{18}$ the small exothermic peak located at about $1320^{\circ} \mathrm{C}$ corresponds to the occurrence of the mullitization reaction.

The dilatometric and corresponding derivative plots are reported in Fig. 2.

The plots are consistent with those reported by Ivankovic et al., ${ }^{18}$ and highlight the different phenomena occurring in the sample. The first peak at $565^{\circ} \mathrm{C}$, practically coincident with the largest exothermic peak in the differential thermal analysis data, was due to the polymer-to-ceramic conversion, which resulted in an increase in the density of the material. The large shrinkage centered around $1320^{\circ} \mathrm{C}$ was related to the formation of mullite. The temperature at which this densification occurred is a reasonable index of the reactivity of the alumina/silica mixture. According to Schneider et al.'s definition, ${ }^{14}$ mullite precursors may be divided into three categories. Type I precursors are single-phase systems featuring an atomic or near-atomic homogeneity in the $\mathrm{Al}-\mathrm{Si}$ mixing, so that they are capable of transforming into mullite at about $980^{\circ} \mathrm{C}$. Type II precursors are diphasic systems consisting of amorphous silica and pseudoboehmite (transforming firstly into $\gamma-\mathrm{Al}_{2} \mathrm{O}_{3}$, and then into $\delta-\mathrm{Al}_{2} \mathrm{O}_{3}$ ), capable of mullitization above $1250^{\circ} \mathrm{C}$. Finally, type III precursors are diphasic systems, non-crystalline up to about $980^{\circ} \mathrm{C}$, in which mullite formation is favored by the formation of weakly crystalline transient phases (such as Al-Si spinel ${ }^{41}$ or $\gamma-\mathrm{Al}_{2} \mathrm{O}_{3}$ ), capable of mullitization at temperatures lower than $1250^{\circ} \mathrm{C}$.
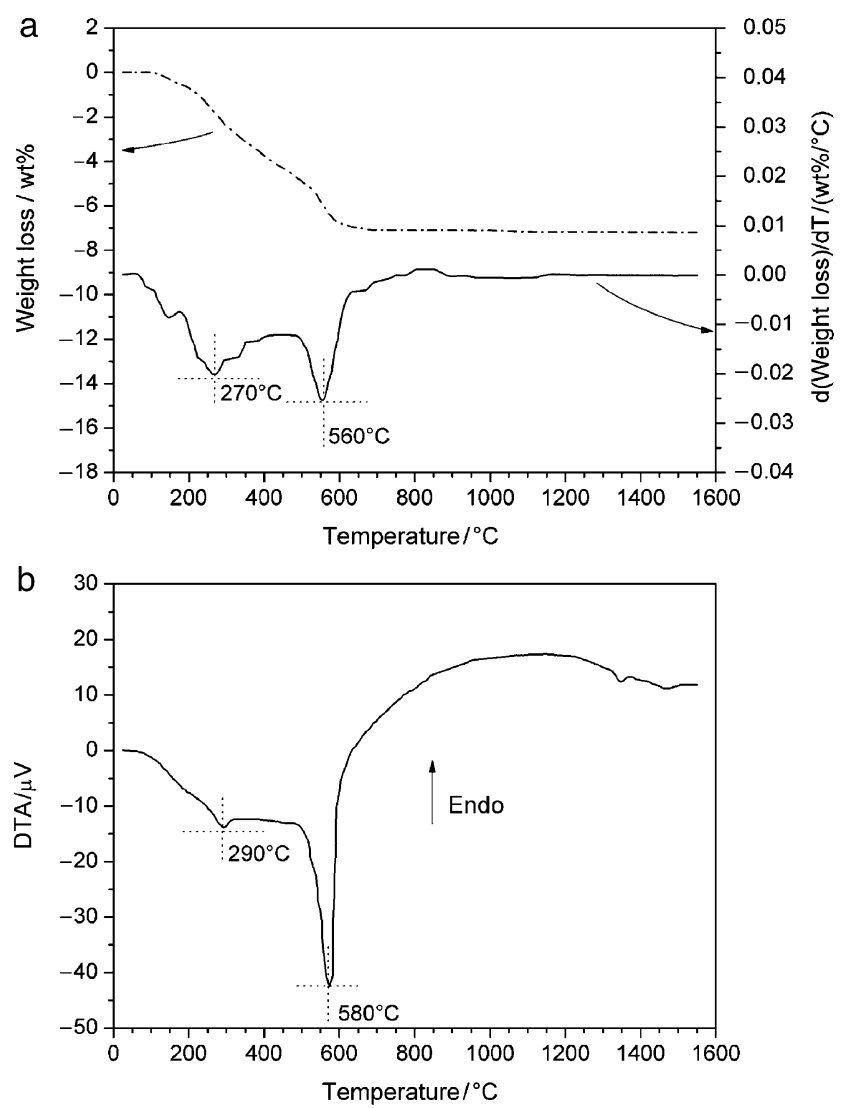

Fig. 1. Thermogravimetric analysis (TGA) (a) and differential thermal analysis (b) patterns for the silicone - nano $\mathrm{Al}_{2} \mathrm{O}_{3}$ mixture; the TGA plot is given along with its first derivative plot. 

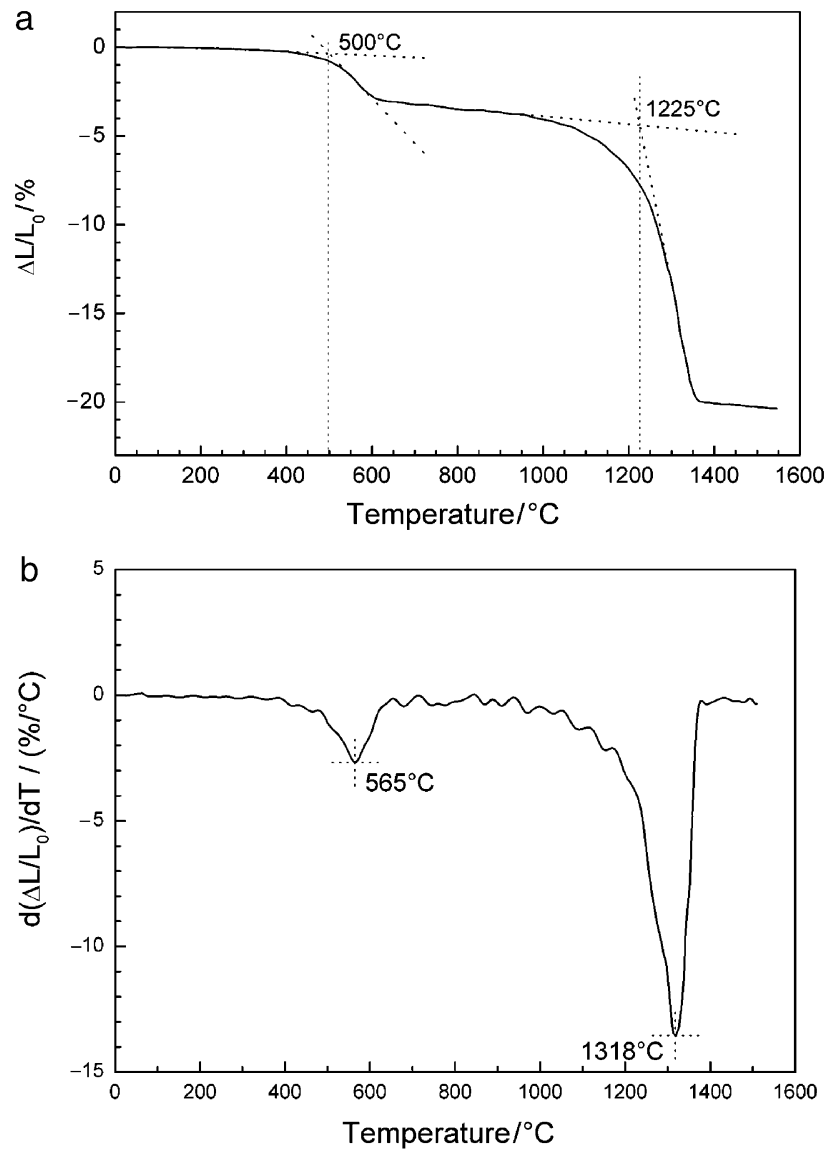

Fig. 2. Dilatometric plots for the silicone- $\operatorname{nanoAl}_{2} \mathrm{O}_{3}$ mixture: (a) direct plot, and (b) derivative plot.

The observed behavior of the investigated preceramic poly$\operatorname{mer} / \gamma-\mathrm{Al}_{2} \mathrm{O}_{3}$ mixture is consistent with that of type II precursors; in particular, it is comparable to the case of reaction sintering of amorphous $\mathrm{SiO}_{2}$-coated $\gamma-\mathrm{Al}_{2} \mathrm{O}_{3}$ particle nanocomposites, as reported by Bartsch et al. ${ }^{3}$ From the derivative plot, it must be noted, however, that the onset of the large densification occurs at about $1200^{\circ} \mathrm{C}$ (see the large curvature before to the peak), suggesting that the investigated mixture possessed good reactivity, and extensive mullitization could be obtained even at temperatures lower than $1320^{\circ} \mathrm{C}$. In addition, the proposed processing method has the significant advantage of mixing and coating $\gamma-\mathrm{Al}_{2} \mathrm{O}_{3}$ nanoparticles with a commercially available preceramic polymer using a simple dissolution/dispersion method compared with sol-gel processing. Furthermore, the produced precursor powders are stable and can be processed using conventional technologies (e.g., extrusion, spinning, cold, or warm pressing) as they contain a meltable, crosslinkable polymer.

The powder XRD analysis, whose results are shown in Fig. 3(a), confirmed what was suggested by the DTA/TGA and dilatometric analyses. Mullitization was found to occur already at $1250^{\circ} \mathrm{C}$, and the chosen dwelling time $(2.5 \mathrm{~h})$ allowed extensive formation of mullite at temperatures below that of the main peak present in Fig. 2(b). The holding time at temperature as well as the heating rate certainly play a significant role in mullite formation, and will be the object of a separate investigation.

The XRD patterns were analyzed and refined by means of Rietveld's method, using the MAUD software package. ${ }^{39}$ An example of the refinements, for the sample fired at $1250^{\circ} \mathrm{C}$, is reported in Fig. 3(b). A remarkably close fitting of the experimental data was obtained, as shown by the flatness of the error function plot reported below the diffraction pattern.
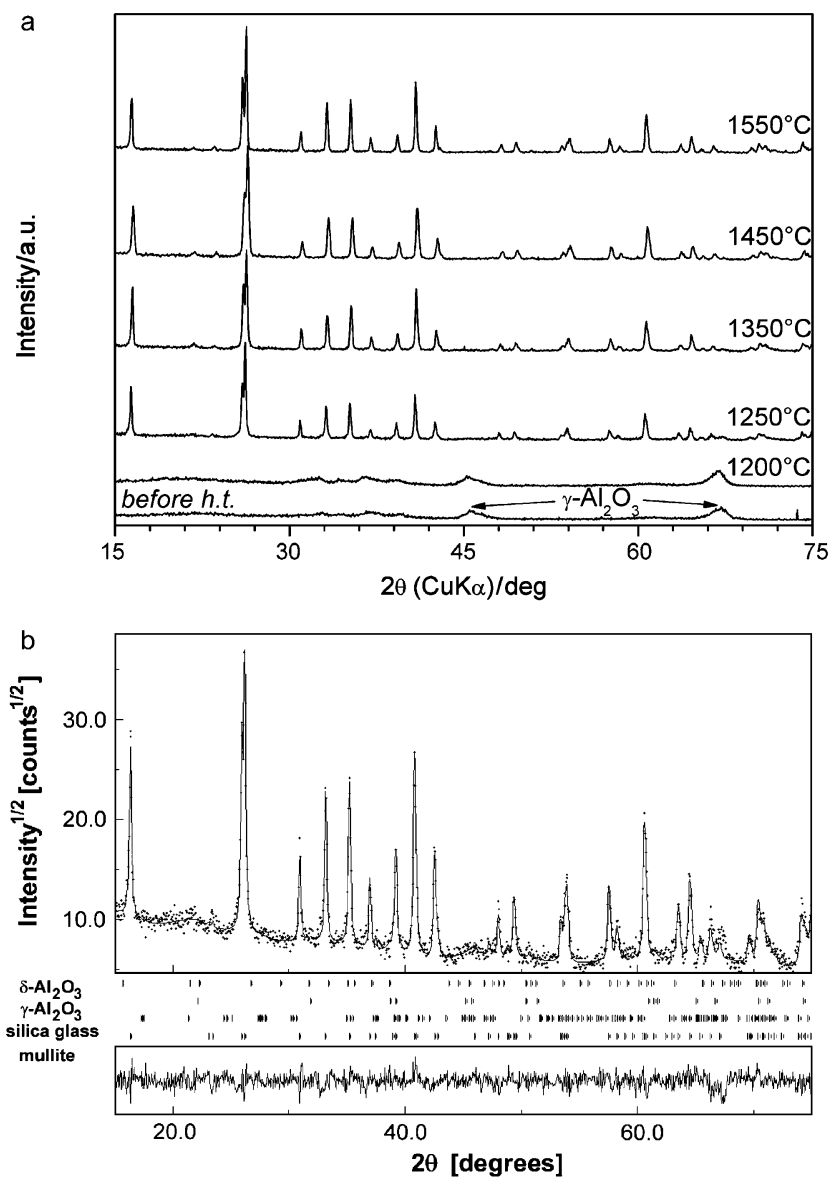

Fig. 3. X-ray diffraction (XRD) analysis of the obtained ceramics: (a) development of the phases as a function of the firing temperature, and (b) example of Rietveld refinement of XRD patterns $\left(1250^{\circ} \mathrm{C}\right.$, the dots correspond to the experimental data, and the straight lines correspond to the calculated patterns).

From the refinement analysis, the volume fraction of mullite and its approximate crystal size were obtained, and the results are shown in Fig. 4.

At the onset of the mullitization, at $1250^{\circ} \mathrm{C}$, a volume fraction of mullite of about $96 \%$ was already formed, leveling out at about $99.5 \mathrm{vol} \%$ above $1350^{\circ} \mathrm{C}$. The remaining phases were identified to be residues from alumina and an amorphous phase identified as silicate glass. Alumina residues were estimated to correspond to $3.3 \mathrm{vol} \%$ at $1250^{\circ} \mathrm{C}$, and could be attributed to a mixture of $\gamma$ - and $\delta-\mathrm{Al}_{2} \mathrm{O}_{3}$ (in the proportions of $0.7 \mathrm{vol} \% \gamma$ and $2.6 \mathrm{vol} \% \delta$ ); the remaining $0.8 \mathrm{vol} \%$ was attributable to the glass phase. The alumina residues almost disappeared at $1350^{\circ} \mathrm{C}$ and at higher temperatures (from $1350^{\circ}$ to $1450^{\circ} \mathrm{C}$ ) only about $0.6 \mathrm{vol} \%$ of glass phase was found, which decreased to $0.1 \mathrm{vol} \%$ at $1550^{\circ} \mathrm{C}$. It must be noted that there was no evidence of cristobalite formation, which was found in other works dealing with the oxidation of analogous preceramic polymers. ${ }^{30,32,38}$ This finding points to the fact that, in comparison with what was reported by Suttor et al..$^{30}$ and in accordance with what was reported by Ivankovic et al. ${ }^{18}$ for sol-gel systems, the nanometric size greatly increases the reactivity of alumina fillers in a silica-rich matrix.

The crystals developed at the lowest temperature, from the reaction between the nanoalumina and the $\mathrm{SiO}_{2}$ ceramic residue from the preceramic polymer, had an average size of about $50 \mathrm{~nm}$; the introduction of a large amount of nanosized alumina inclusions in the preceramic polymer acted as nucleation centers for numerous mullite crystals, limiting their grain growth. Even if the formation of the mullite phase increased very rapidly with increasing firing temperature, the grain size did not increase, 


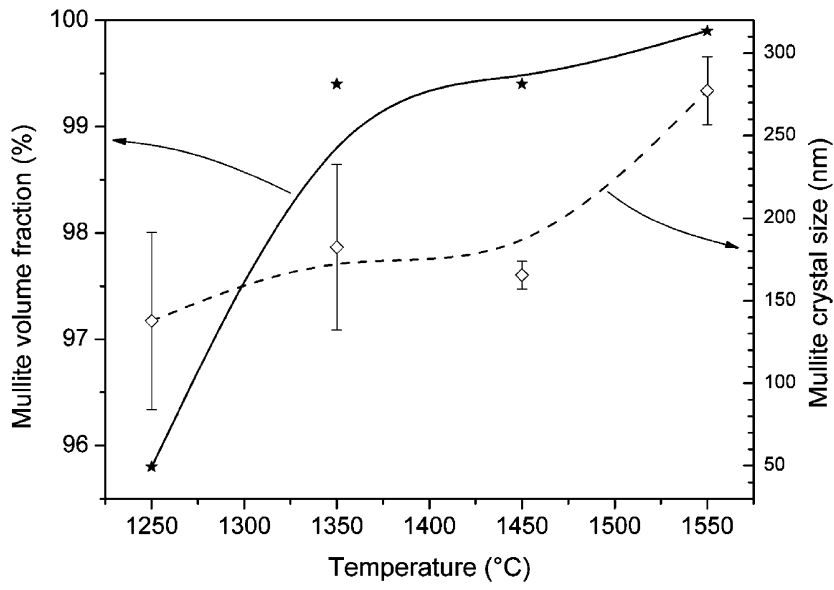

Fig. 4. Mullite volume fraction and crystal size as a function of the firing temperature.

except for the treatment at the maximum temperature: $1550^{\circ} \mathrm{C}$. This finding is consistent with the previously observed low interdiffusion rate (below $2.33 \times 10^{-17} \mathrm{~cm}^{2} / \mathrm{s}$, estimated by using Aksay's equation $\left.D=3.23 \times 10^{3} \exp \{-703000 \mathrm{~J} / \mathrm{RT}\}\right)^{42}$ of Si $^{4+}$ and $\mathrm{Al}^{3+}$ ions within the mullite lattice, which causes poor solidstate sinterability of mullite powder compacts. ${ }^{5,26}$ Additionally, the very fine microstructure produced might have a positive effect on the mechanical properties, which will be the object of a separate investigation.

SEM and TEM investigations confirmed and completed the results of the XRD analysis. The SEM micrographs in Fig. 5 illustrate that crack-free samples, with a very limited residual porosity, were produced. As shown in Figs. 5(b), (d), (f), the fracture surface roughness increased with increasing firing temperature, in agreement with the growth in size and amount of the mullite crystals. The micrographs also showed that the samples were well densified, and contained a limited amount of pores and defects (the residual porosity at $1550^{\circ} \mathrm{C}$ was measured by gas pycnometry to be about $2.6 \mathrm{vol} \%$ ).

TEM investigations, coupled with high-resolution imaging (HREM), were performed to follow the mullitization process with increasing temperature. Samples treated at $1200^{\circ} \mathrm{C}$ revealed a highly defective grain structure, due to the dispersion of $\mathrm{Al}_{2} \mathrm{O}_{3}$ nanoparticles $(10-50 \mathrm{~nm}$ in diameter, see Fig. 6(a)). These particles are clearly visible from the high-resolution images, as illustrated by Fig. 6(b), in which ordered zones, showing crystal lattice planes, are surrounded by an amorphous matrix, resulting from the $\mathrm{SiO}_{2}$ ceramic residue of the preceramic polymer. The dimensions of these nanocrystals are coincident with the reported crystal size of the starting $\mathrm{Al}_{2} \mathrm{O}_{3}$ nanoparticles. In general, the particles also had an irregular shape. It should be noted that there is no evidence of particle agglomeration, as can be seen in Fig. 6(a), indicating that the proposed procedure for dispersing nanosized alumina in the preceramic polymer allows to reach a remarkable homogeneity.
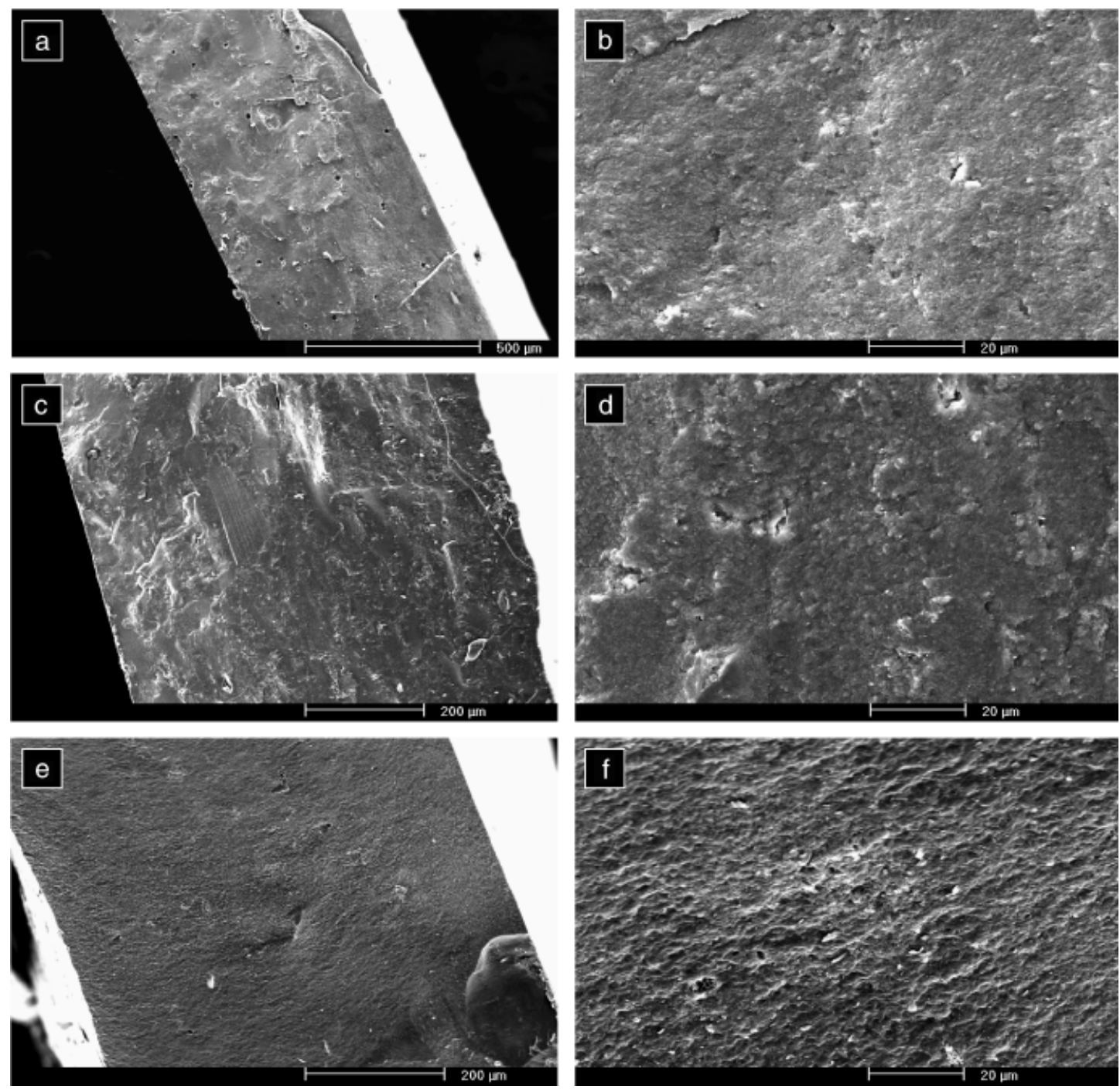

Fig. 5. Scanning electron microscope micrographs of selected samples; (a, b) $1250^{\circ} \mathrm{C}$; (c, d) $1400^{\circ} \mathrm{C}$; and (e, f) $1550^{\circ} \mathrm{C}$. 

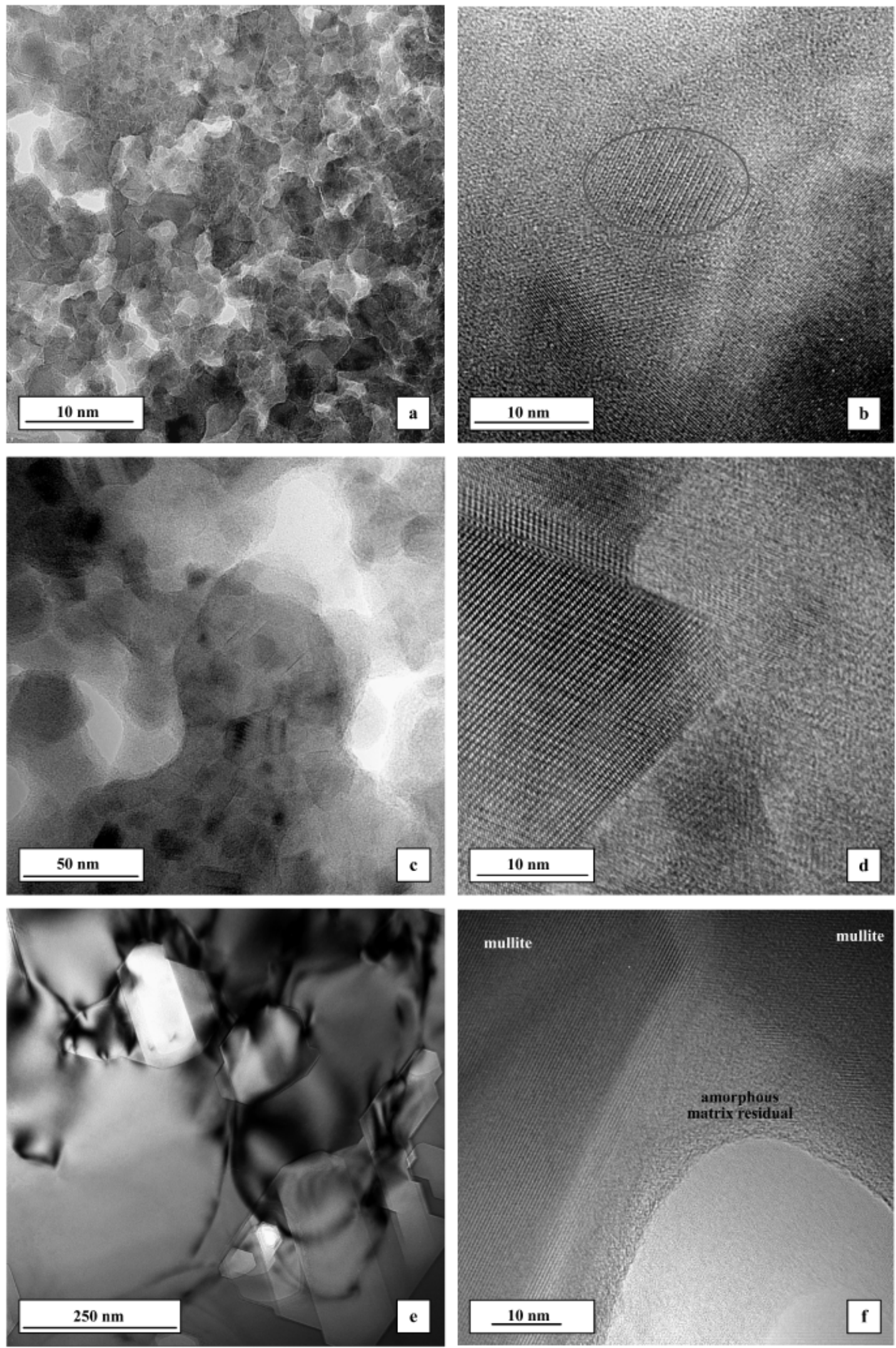

Fig. 6. Transmission elecron microscope and high-resolution electron microscope images of selected samples $(\mathrm{a}, \mathrm{b}) 1200^{\circ} \mathrm{C}$; $\left(\mathrm{c}\right.$, d) $1250^{\circ} \mathrm{C}$; and (e,f) $1550^{\circ} \mathrm{C}$

In the case of samples heated at $1250^{\circ} \mathrm{C}$, larger crystals are visible (see Fig. 6(c)), with well-developed crystallographic edges; the crystals correspond to mullite as proved by their lattice plane distance of about $0.65 \mathrm{~nm}$ measured from HREM images (see Fig. 6(d)). The mullite crystals still appear to be encapsulated in a silica amorphous matrix (cf. the EDX results below).
Finally, on firing at $1550^{\circ} \mathrm{C}$, mullite crystals with diameters in the range $200-400 \mathrm{~nm}$ were obtained as shown in Fig. 6(e). Besides mullite, crystallographically shaped intragranular pores and characteristic grain triple junctions were observed, with a limited amount of amorphous material being visible in the triple junctions (see Fig. 6(f)). 


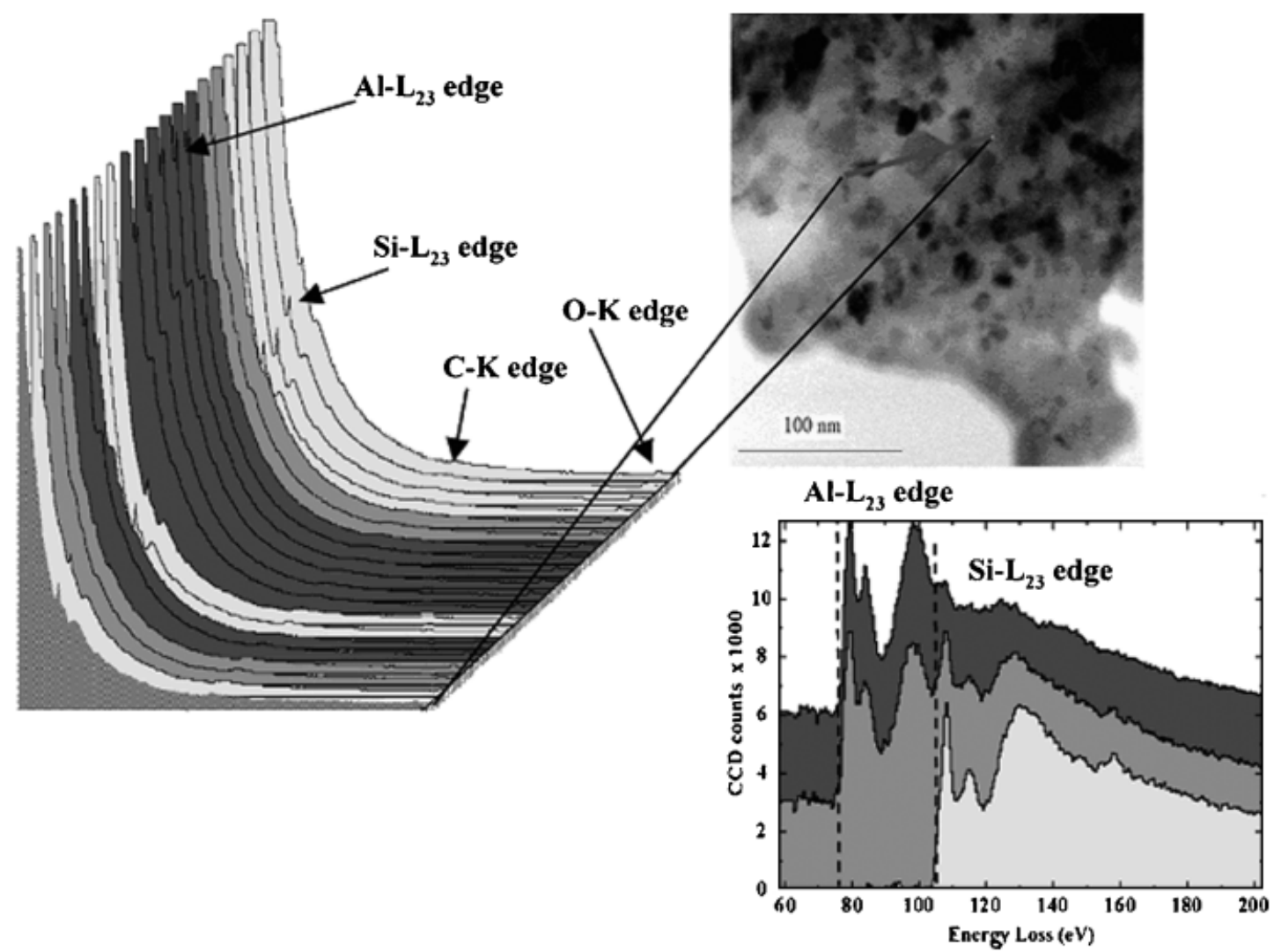

Fig. 7. Electron energy-loss spectroscopy (EELS) analysis of a sample heated at $1250^{\circ} \mathrm{C}$, performed along a line crossing several grains (upper right: scanning transmission electron microscope image, left: recorded EEL spectra, lower right: energy-loss near-edge structures (ELNES) of selected spectra).

The chemical composition of the observed structures was investigated by applying the microscopic scanning mode (STEM) and performing EEL spectra with a resolution of a few nanometers. In the case of the material fired at $1250^{\circ} \mathrm{C}$, Fig. 7 shows the related EEL spectra obtained by scanning across several nanograins separated by amorphous regions. The fine structure of the Si- and $\mathrm{Al}-\mathrm{L}_{23}$ edges of some selected spectra (lower right in Fig. 7) was found to correlate with that of mullite in the area of the crystals (dark gray spectrum) and with that of $\mathrm{SiO}_{2}$ in between (light gray spectrum). This means that in this material, mullite grains of some tens of nanometers in diameter were embedded in an amorphous silicon dioxide matrix deriving from the pyrolysis of the preceramic polymer. The spectrum in the middle in Fig. 7, lower right (medium gray), indicates a simple superposition of both these spectra, resulting from the simultaneous penetration of a grain and the matrix within the thin TEM sample. The amorphous material in the triple junctions of the samples fired at $1550^{\circ} \mathrm{C}$ is also mainly comprised of silica glass. According to the EELS spectrum (see Fig. 8), the peak

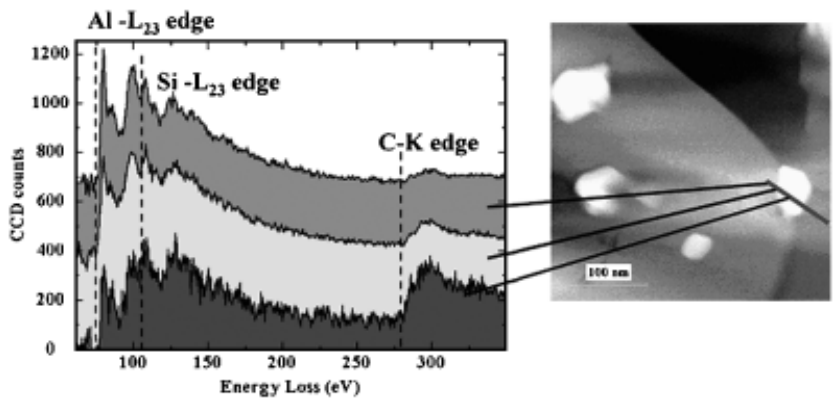

Fig. 8. Electron energy-loss spectroscopy (EELS) analysis of a sample heated at $1550^{\circ} \mathrm{C}$ in the region of a triple grain junction (right: scanning transmission electron microscope image, left: energy-loss near-edge structures of selected EEL spectra). ratio of the $\mathrm{Si}-\mathrm{L}_{23}$ edge to the $\mathrm{Al}-\mathrm{L}_{23}$ edge was higher in the triple junction (dark gray spectrum) than in mullite (medium gray spectrum), which hints at a higher silicon content in that region that has been derived from the pyrolyzed polymer.

\section{Conclusions}

The use of alumina nanosized particles coupled with a commercially available silicone resin proved very effective for the preparation of high-purity, monolithic, crack-free mullite ceramics. The high chemical reactivity of the inclusions toward the silicarich residue deriving from the preceramic polymer, coupled with their homogeneous distribution, allowed to achieve a high rate of mullitization at low temperatures, comparable to those obtained for more complex diphasic gel formulations. The preparation of silicone/alumina nanocomposites could be particularly profitable for the production of variously shaped ceramic objects using conventional plastic-forming technologies.

\section{Acknowledgments}

The authors are indebted to Dr. K. Deller of Degussa AG (Hanau, Germany) for his assistance, and to Dr. F. D. Classen of Eigenman Veronelli S. p. A. (Milan, Italy) for kindly providing the $\gamma$-alumina nanoparticles (Aeroxide AluC). E. B. acknowledges Prof. Amedeo Maddalena (Dipartimento di Ingegneria MeccanicaSettore Materiali, Università di Padova) for a very fruitful and stimulating discussion on fitting the XRD data by means of Rietveld's method, and Prof. Luca Lutterotti and his group (Dipartimento di Ingegneria dei Materiali, Università di Trento) for freely supplying the MAUD program package. The authors thank C. Furlan of CUGAS, Padova, for performing SEM investigations.

\section{References}

${ }^{1}$ H. Schneider, "Thermal Expansion of Mullite," J. Am. Ceram. Soc., 73, 2073-6 (1991)

${ }^{2}$ V. Viswabaskaran, F. D. Gnanam, and M. Balasubramanian, "Mullitisation Behaviour of Calcined Clay-Alumina Mixtures," Ceram. Int., 29, 561-71 (2003). 
${ }^{3}$ M. Bartsch, B. Saruhan, M. Schmucker, and H. Schneider, "Novel Low-Temperature Processing Route of Dense Mullite Ceramics by Reaction Sintering of Amorphous $\mathrm{SiO}_{2}$-Coated $\gamma$-Alumina Particle Nanocomposites," J. Am. Ceram. Soc., 74, 2448-52 (1999).

${ }^{4}$ V. Viswabaskaran, F. D. Gnanam, and M. Balasubramanian, "Mullitisation Behaviour of South Indian Clays," Ceram. Int., 28, 557-64 (2002).

${ }^{5}$ V. Viswabaskaran, F. D. Gnanam, and M. Balasubramanian, "Mullite from Clay-Reactive Alumina for Insulating Substrate Application,” Appl. Clay Sci., 25, 29-35 (2004).

${ }^{6} \mathrm{~T}$. Ebadzadeh and W. E. Lee, "Processing-Microstructure-Property Relations in Mullite-Cordierite Composites," J. Eur. Ceram. Soc., 18, 837-48 (1998).

${ }^{7}$ S. Somiya and Y. Hirata, "Mullite Powder Technology and Applications in Japan," Bull. Am. Ceram. Soc., 70, 1624-32 (1991).

${ }^{8}$ H. Schneider, K. Okada, and J. Pask, Mullite and Mullite Ceramics. John Wiley and Sons Ltd, Chichester, UK, 1-251, (1994).

${ }^{9}$ I. Aksay, D. M. Dabbs, and M. Sarikaya, "Mullite for Structural, Electronic, and Optical Applications," J. Am. Ceram. Soc., 74, 2343-58 (1991).

${ }^{10}$ W.-Ch. Wei and J. W. Halloran, "Transformation Kinetics of Diphasic Aluminosilicate Gels," J. Am. Ceram. Soc., 71, 581-7 (1988).

${ }^{11}$ D. X. Li and W. J. Thomson, "Mullite Formation Kinetics of a Single-Phase Gel," J. Am. Ceram. Soc., 73, 964-9 (1990).

${ }^{12}$ D. X. Li and W. J. Thomson, "Mullite Formation from Non-Stoichiometric Diphasic Precursors," J. Am. Ceram. Soc., 74, 2382-7 (1991).

${ }^{13}$ A. Taylor and D. Holland, "The Chemical Synthesis and Recrystallisation Sequence of Mullite," J. Non-Cryst. Solids, 152, 1-7 (1993).

${ }^{14}$ H. Schneider, D. Voll, B. Saruhan, J. Sanz, G. Schrader, C. Rüscher, and A. Mosset, "Synthesis and Structural Characterization of Non-Crystalline Mullite Precursors," J. Non-Cryst. Solids, 178, 262-71 (1994).

${ }^{15}$ D. Amutharani and F. D. Gnanam, "Low Temperature Pressureless Sintering of Sol-Gel Derived Mullite," Mater. Sci. Eng. A, 264, 254-61 (1999).

${ }^{16}$ K. J. D. MacKenzie, R. H. Meinhold, J. E. Patterson, H. Schneider, M Schmucker, and D. Voll, "Structural Evolution in Gel-Derived Mullite Precursors," J. Eur. Ceram. Soc., 16, 1299-308 (1996).

${ }^{17}$ G. D. Sorarù, H.-J. Kleebe, R. Ceccato, and L. Pederiva, "Development of Mullite-SiC Nanocomposites by Pyrolysis of Filled Polymethylsiloxane Gels," J. Eur. Ceram. Soc., 20, 2509-17 (2000).

${ }^{18}$ H. Ivankovic, E. Tkalcec, R. Nass, and H. Schmidt, "Correlation of the Precursor Type with Densification Behavior and Microstructure of Sintered Mullite Ceramics," J. Eur. Ceram. Soc., 23, 283-92 (2003).

${ }^{19}$ E. Tkalcec, H. Ivankovic, R. Nass, and H. Schmidt, "Crystallization Kinetics of Mullite Formation in Diphasic Gels Containing Different Alumina Components," J. Eur. Ceram. Soc., 23, 1465-75 (2003).

${ }^{20}$ S. P. Chaudhuri and S. K. Patra, "Preparation and Characterization of Transition Metal Ion Doped Mullite,” Trans. Br. Ceram. Soc., 97, 105-111 (1997).

${ }^{21}$ S. Somiya, M. Yoshimura, M. Suzuki, and T. Yanaguchi, "Mullite Powder from Hydrothermal Processing"; pp. 287-317 in Ceramic Transactions Mullite and Mullite Matrix Composites, Vol. 6, Edited by S. Somiya, R. F. Davies, and J. A. Pask. American Ceramic Society, Westerville, OH, 1990.

${ }^{22}$ C. Kaya, X. Gu, I. Al-Dawery, and E. G. Butler, "Microstructural Development of Woven Mullite Fibre-Reinforced Mullite Ceramic Matrix Composites by Infiltration Processing," Sci. Techol. Adv. Mater., 3, 35-44 (2002).

${ }^{23}$ Y. Hirata, I. A. Aksay, R. Kurita, S. Hori, and H. Kaji, "Processing of Mullite Powders Processed by CVD"; pp. 119-26 in Ceramic Transactions Mullite and Mullite Matrix Composites, Vol. 6, Edited by S. Somiya, R. F.
Davies, and J. A. Pask. American Ceramic Society, Westerville, OH, 1990.

${ }^{24}$ M. D. Sacks, N. Bozkurt, and G. W. Scheiffele, "Fabrication of Mullite and Mullite-Matrix Composites by Transient Viscous Flow Sintering of Composite Powders," J. Am. Ceram. Soc., 74, 2428-37 (1991).

${ }^{25}$ M. D. Sacks, Y.-J. Lin, G. W. Scheiffele, K. Wang, and N. Bozkurt, "Effect of Seeding on Phase Development, Densification Behavior, and Microstructure Evolution in Mullite Fabricated from Microcomposite Powders," J. Am. Ceram. Soc., 78, 2897-906 (1995).

${ }^{26}$ M. D. Sacks, K. Wang, G. W. Scheiffele, and N. Bozkurt, "Effect of Composition on Mullitization Behavior of $\alpha$-Alumina/Silica Microcomposite Powders," J. Am. Ceram. Soc., 80, 663-72 (1997).

${ }^{27}$ K. G. Liu and G. Thomas, "Time-Temperature Transformation Curves for Kaolinite- $\alpha$-Alumina," J. Am. Ceram. Soc., 77, 1545-52 (1994).

${ }^{28}$ M. A. Sainz, F. J. Serrano, J. M. Amigo, J. Bastida, and A. Caballero, "XRD Microstructural Analysis of Mullites Obtained from Caolinite-Alumina Mixtures," J. Eur. Ceram. Soc., 20, 403-12 (2000).

${ }^{29}$ M. D. Sacks and H.-W. Lee, "A Review of Powder Preparation Methods and Densification Procedures for fabricating High Density Mullite"; pp. 167-207 in Ceramic Transactions Mullite and Mullite Matrix Composites, Vol. 6, Edited by S. Somiya, R. F. Davies, and J. A. Pask. American Ceramic Society, Westerville, OH, 1990.

${ }^{30}$ D. Suttor, H.-J. Kleebe, and G. Ziegler, "Formation of Mullite from Filled Siloxanes," J. Am. Ceram. Soc., 80, 2541-8 (1997).

${ }^{31}$ T. Michalet, M. Parlier, A. Addad, R. Duclos, and J. Crampon, "Formation at Low Temperature with Low Shrinkage of Polymer $/ \mathrm{Al} / \mathrm{Al}_{2} \mathrm{O}_{3}$ Derived Mullite," Ceram. Int., 27, 315-19 (2001).

${ }^{32}$ T. Michalet, M. Parlier, F. Beclin, R. Duclos, and J. Crampon, "Elaboration of Low Shrinkage Mullite by Active Filler Controlled Pyrolysis of Siloxanes," J. Eur. Ceram. Soc., 22, 143-52 (2002).

${ }^{33}$ J. Anggono and B. Derby, "Intermediate Phases in Mullite Synthesis via Aluminum- and Alumina-Filled Polymethylsiloxane," J. Am. Ceram. Soc., 88 2085-91 (2005).

${ }^{34}$ G. M. Renlund, S. Prochazka, and R. H. Doremus, "Silicon Oxycarbide Glasses: Part I. Preparation and Chemistry," J. Mater. Res., 6, 2716-22 (1991).

${ }^{35}$ G. M. Renlund, S. Prochazka, and R. H. Doremus, "Silicon Oxycarbide Glasses: Part II. Structure and Properties," J. Mater. Res., 6, 2723-34 (1991)

${ }^{36}$ M. J. Wild and P. Buhler, "On the Phase Composition of Polymethylsiloxane Derived Ceramics," J. Mater. Sci., 33, 5441-4 (1998).

${ }^{37}$ P. Greil, "Active-Filler-Controlled Pyrolysis of Preceramic Polymers," J. Am. Ceram. Soc., 78, 835-48 (1995).

${ }^{38}$ E. Bernardo, P. Colombo, and E. Manias, "SiOC Glass Modified by Montmorillonite Clay," Ceram. Int., in press.

${ }^{39}$ http://www.ing.unitn.it/ luttero/maud

${ }^{40}$ R. Harshe, C. Balan, and R. Riedel, "Amorphous Si(Al)OC Ceramic from Polysiloxanes: Bulk Ceramic Processing, Crystallization Behavior and Applications," J. Eur. Ceram. Soc., 24, 3471-82 (2004).

${ }^{41}$ K. Okada and N. Otsuka, "Characterization of the Spinel Phase from $\mathrm{SiO}_{2}-$ $\mathrm{Al}_{2} \mathrm{O}_{3}$ Xerogels and the Formation Process of Mullite," J. Am. Ceram. Soc., 69, 652-6 (1986).

${ }^{42}$ Y. Sung, "Kinetics Analysis of Mullite Formation Reaction at High Temperatures," Acta. Mater., 48, 2157-62 (2000). 